\title{
Espetáculo da miscigenação ${ }^{1}$
}

\author{
LILIA MORITZ SCHWARCZ
}

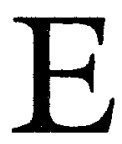

m finais do século XIX o Brasil era recorrentemente descrito como uma imensa nagão mestiga representando, nesse sentido, um caso extremo e singular. "J'ai remarqué un fait singulier..." - dizia o naturalista Gustave Aimard, viajante francês que esteve no Brasil em 1887 - "...que je $n$ 'ai observé qu'au au Brésil: c'est le changement que s'est opéré dans la population par les croisement des races, ils sont les fils du sol".

Mestiça era também a imagem que Louis Agassiz (1868:71) formava do Brasil; esse país que se tornara uma espécie de paraíso dos naturalistas. Dizia o reconhecido pesquisador suíço: " ...que qualquer um que duvide dos males da mistura de rafas, e inclua por mal-entendida filantropia, a botar abaixo todas as barreiras que as separam, venha ao Brasil. Não poderá negar a deterioraf̧ão decorrente da amálgama das raças mais geral aqui do que em qualquer outro pais do mundo, e que vai apagando rapidamente as melhores qualidades do branco, do negro e do indio deixando um tipo indefinido, hibrido, deficiente em energia física e mental".

O Conde Arthur de Gobineau, que permaneceu no Brasil durante quinze meses em missão oficial, também dedicou palavras duras quando tratou de descrever a situafấo racial que observara: "Trata-se de uma população totalmente mulata, viciada no sangue e no espirito e assustadoramente feia" (in: Raeders, 1988:96).

Essa visão mestiça da nação não se resumia, porém, ao olhar que vinha de fora, aos inúmeros naturalistas que aqui estiveram. Internamente o tema se reproduzia a partir de diferentes locais. Nos censos, nos jornais, nas pinturas, na visão de políticos e cientistas, raça aparecia como um argumento partilhado, uma interpretação interna bastante consensual. "Formamos um paiz mestifo... somos mestiços se não no sangue ao menos na alma", definia o crítico literário Silvio Romero (1888), da Escola de Recife, ao comentar " a composiçâo etnica e antbropologica singular" da população brasileira.

João Batista Lacerda (1911), então diretor do Museu Nacional do Rio de Janeiro, na condição de representante de "um thipico paiz misci- 
genado", era convidado a participar do I Congresso Internacional das Rafas, realizado em julho de 1911, apresentando uma tese cujo título já era em si revelador: Sur les métis au Brésil. Nesse ensaio, o país não era apenas caracterizado como mestiço, como se exaltava a mudança operante no local: " o Brasil mestiģo de hoje tem no branqueamento em um século sua perspectiva, saida e solufão".

Partindo dos recintos médicos baianos, era também com esse sentido que em 1894 Nina Rodrigues ponderava: "se um pais não é velho para se venerar ou rico para se fazer representar, precisa ao menos tornar-se interessante". Revelando uma posiçáo bastante lúcida, o conhecido médico aglutinava percepçóes da época. Com efeito, o que resumia a singularidade local, não era mais a flora, a fauna ou a pujança da terra, e sim uma composição racial singular, um certo espetáculo da miscigenação.

\section{O medo da degeneração}

Saudada pelos cientistas estrangeiros como fenômeno desconhecido e recente, a miscigenação transformava-se em tema polêmico entre as elites locais. De um lado, o problema racial é a linguagem pela qual se torna possível apreender as particularidades observadas. Como bem mostrou Hobsbawm (1987), nesse contexto em que discursos raciais vinculavam-se a projetos de cunho nacionalista, soava correto imaginar uma nação em termos biológicos, ou estimar uma futura homogeneidade, como previa Lacerda. Por outro lado, no entanto, a constatação de que essa era uma nafăo mestifa gerava novos dilemas para os cientistas brasileiros. Se falar na raça parecia oportuno - já que a questão referendava-se empiricamente e permitia certa naturalizaçăo de diferenças, sobretudo sociais -, o mesmo tema gerava paradoxos: implicava admitir a inexistência de futuro para uma naçáo de raças mistas como a nossa. Isto é, o conjunto dos modelos evolucionistas náo só elogiava o progresso e a civilizaçáo, como concluía que a mistura de raças heterogêneas era sempre um erro, e levava à degeneração não só do indivíduo como de toda a coletividade.

Evidenciava-se a defasagem entre as teorias deterministas que chegavam de fora quando pensadas em funçáo da realidade mestifa de dentro e a rigidez da teoria quando o objeto em questão era a naçáo brasileira. A saída foi então preconizar a adoçáo do ideário científico, porém, sem seu corolário teórico - aceitar a idéia da diferença ontológica entre as raças sem a condenação à hibridaçáo - à medida em que o país, a essas alturas, encontrava-se irremediavelmente miscigenado. 
Incômoda era a situação desses intelectuais que oscilavam entre a adoçáo de modelos deterministas e a verificaçáo de que o país, pensado nesses termos, era inviável. "Devia ser difícil abrir mão da crítica externa e de uma certa internalização desse tipo de visão estrangeira a respeito do Brasil como país aberrante", afirma Roberto Ventura (1991:91). Afinal, em um momento em que se redescobria a mesma naçáo, era como obstáculos à civilizaçăo barreiras à identidade nacional que os grupos indígenas, africanos e mestiços eram incorporados (Queiroz, 1989:32).

\section{Entre bomens de sciencia}

O mais interessante é, portanto, tendo em mente essa representafăo mestiça do país, entender a relevância e originalidade desse tipo de teoria que, no Brasil, conheceu seu momento de maior influência no período que vai de 1870 a 1930 . Modelo de sucesso na Europa de meados dos oitocentos, as teorias raciais chegam tardiamente ao Brasil, recebendo, porém, uma entusiástica acolhida, em especial nos diversos estabelecimentos de ensino e pesquisa, que na época congregavam boa parte da reduzida elite pensante nacional.

O momento selecionado é particularmente significativo não só porque aglutina uma série de episódios relevantes - o final da Guerra do Paraguai, a fundação do Partido Republicano, a promulgação da lei do Ventre Livre - , como por anunciar a entrada de novos modelos científico-deterministas e o amadurecimento de alguns centros de ensino e pesquisa nacionais, como os institutos históricos, os museus etnográficos, as faculdades de direito e de medicina.

Nesses locais, o tema racial esteve particularmente presente, mas náo de forma unívoca. Raça aparece enquanto um conceito de negociaçáo, sendo que as interpretaçôes variaram, assim como eram diversas as metas e especificidades de cada um desses estabelecimentos.

As personagens que integram essas instituições, são esses - hoje - obscuros homens de sciencia que em finais do século XIX, e do interior dos locais em que trabalhavam, tomaram para si a quixotesca tarefa de abrigar uma ciência positiva e determinista, e, utilizando-se dela, procuraram liderar e dar saídas para o destino desta nação. Misto de cientistas e políticos, pesquisadores e literatos, esses intelectuais irăo se mover nos incômodos limites que os modelos lhes deixavam, haja visto que, nesse momento, indagar sobre que naçáo era essa significava, de alguma maneira, se perguntar sobre que raça era a nossa ou, entáo, se uma 
mestiçagem tão extremada não seria um sinal em si de decadência e enfraquecimento.

\section{Raça: um conceito negociado}

O fin-de-siecle brasileiro era vivenciado nesses meios, dessa maneira, com grande dose de pessimismo. Com efeito, esses cientistas, ao mesmo tempo que se encontravam desiludidos com as promessas de igualdade, indagavam-se sobre as causas persistentes das diferenças entre os homens.

Nos museus etnográficos de Belem, São Paulo e Rio de Janeiro, por exemplo, a ampla utilização de argumentos evolucionistas permitiu explicar cientificamente as diferenças, classificar as espécies, localizar os pontos de atraso. Partindo dos modelos das ciência naturais, esses pesquisadores buscavam uma ponte entre as espécies botânicas, zoológicas e a humanidade, que pudesse prever, como pretendia Herman von Thering (então diretor do Museu Paulista) um desenvolvimento comum: " a degenerescencia presente nos tipos bibridos na zoologia pode ser com certa facilidade percebida nos grupos bumanos... Longe dos tipos puros é com cuidado que depe ser analisada a miscigenafáo local" (Revista do Museu Paulista, 1897).

Adeptos, em sua maior parte, dos modelos poligenistas de análise - que entendiam as raças como fenômenos essenciais e ontológicos, resultantes de centros de criação diversos - concluíam, esses teóricos dos museus, náo só que "a evoluçaio encontrada na natureza era exatamente igual àquela esperada para os bomens" (Boletion do Musen Paraense E. Goeldi), como supunham que "os grupos inferiores constituiam barreiras frente ao progresso da civilizagáo". E ilustrativa, nesse sentido, a defesa que faz von Thering em 1911, no jornal O Estado de S. Paulo, do extermínio dos Kaingang, em nome da construçăo da estrada de ferro Noroeste do Brasil. Utilizando-se de modelos evolucionistas e deterministas, o naturalista alemáo condenava "grupos indigenas inferiores", que, em sua ótica, desapareceriam pela " mera afáo da natureza". Frente aos prognósticos científicos, nada havia a obstar; nem mesmo " uma moral de fundo bumanista", como afirmava Von Ihering (2).

Cumpriam os museus etnográficos no país, portanto, um papel específico. Ao mesmo tempo em que ajudaram a popularizar no exterior a imagem de que o Brasil seria um grande laboratório racial, introduziram um olhar particular. O olhar do naturalista que classifica conjuntamente a flora, a fauna e o homem em suas produçóes. " $A$ perfectibilidade humana fard seu papel no Brasil, assim como a natureza náo cessa de 
agir nas especies pegetais e animais", dizia Goeldi na revista de seu museu, acreditando em um processo evolutivo para a desacreditada populaçáo nacional.

Nos institutos históricos, por sua vez - e em especial nos estabelecimentos carioca, paulista e pernambucano -, a entrada tardia dos modelos deterministas levou à utilizaçáo de explicaçóes variadas: uma visão otimista, católica e patriótica, paralela a uma concepção determinista e evolutiva da naçáo. O resultado foi um modelo que acomodou explicaçóes de teor monogenista - que concebia a humanidade enquanto una em sua origem e desenvolvimento -, mas que não se furtou a recorrer a argumentos darwinistas sociais quando se tratava de justificar hierarquias sociais consolidadas. "Abrem-se-me então os olhos e percebo que taes bomens ja nao vivem na innocencia paradisiaca e que as theorias de Jean Jacques Rousseau são meros sonbos. ...Os americanos näo representam uma rafa selpagem, representam antes uma rafa degenerada que se tornou selpagem. ...Assim poucos séculos se passarcio e o ultimo americano deitar-se-á. Se não se garantir a superioridade do sangue branco toda a populagáo do continente definbará (Revista do Instituto Histórico de Säo Paulo, 1904:53-4).

Nem bem descobridores, nem bem missionários, esses cientistas ora encontravam uma nação a admirar, ora se debruçavam com temor sobre seu país, propondo - no lápis e papel - reformas e saídas que, em última instância, dependiam de sua própria atuação. Nesse sentido, talvez o debate tenha mesmo se concentrado entre as escolas de direito e medicina. Instaurada uma disputa pela hegemonia e predomínio científico no país, percebem-se dois contendores destacados. De um lado o remédio, de outro a lei; o veneno previsto para uns, o antídoto nas mãos dos outros.

Para os bomens de direito a responsabilidade de conduzir a nação estava vinculada à elaboraçáo de um código unificado, que tornasse homogêneas as grandes diferenças observáveis: " $O$ Estado é necessdrio... É uma formafão necessária... e que resulta de uma evolufăo social, que vinculada aos hommens de lei imprime uma única direçäo a sociedade... Por fim 6 a forga o elemento gerador do Estado, ella se manifesta acima da luta das rafas ou de grupos entre nós tä́o heterogeneos (Revista Academica da Faculdade de Direito de Recife, 1922:103). Caberia, assim, exclusivamente aos legisladores e através do exercício da lei, unificar esse território que se queria naçăo.

No entanto, no caso das escolas de direito, se existiam concep̧̧óes partilhadas, a amarra institucional não chegou a encobrir diferenças teóricas fundamentais: $o$ argumento racial construído por Recife, contras- 
tou com a interpretação liberal da academia paulista. De fato, partiam de Recife as leituras germânicas sobre as determinaçóes das raças e a defesa - que consagrou a figura de Silvio Romero - de uma mestiçagem moral e física enquanto recurso de unidade nacional. Já a escola paulista analisava com cautela a introduçáo dos modelos darwinistas sociais, com " a critica de quem reconbece a verdade de alguns conceito $e$ repele os exageros desses juris consultos..." (Rerista da Faculdade de Direito de São Paulo, 1906:67).

As duas escolas, porém, revelaram possuir projetos bastantes coincidentes e harmônicos ora quando se tratava de defender a hegemonia da prática do Direito, ora quando se buscava garantir uma certa hierarquia social. Nesse caso, $o$ argumento escorregava da cultura para a natureza, do indivíduo para o grupo, da cidadania para a raça.

Revelador é o debate sobre a entrada de imigrantes asiáticos e africanos, tônica central de várias sessóes na Câmara de Deputados e de outras instâncias atuantes durante os anos $\mathbf{8 0}$ do século passado. Com efeito, partiu de São Paulo a política mais restritiva e que propôs graves entraves à introdução de mão-de-obra negra e oriental. Nesse caso, São Paulo demonstrou na prática o quanto era permeável às conclusóes teóricas racistas e darwinistas sociais, táo populares em Recife. Sempre em nome de um projeto eugênico de depuração das raças, a bancada paulista - "composta pelos dignissimos bacharéis da escola paulista de Direito" (Atas, 1881) - limitou a admissão a apenas alguns países, criticando duramente o que chamava ser "as características amorais dos africanos e dos chins", entendidos como "inassimiláveis, portadores de línguas e costumes estranhos aos nossos, praticantes do suicídio e do ópion" (Nogueira, 1984; Hall, 1976; Monteiro, 1992).

Dessa maneira, enquanto na Escola de Recife um modelo claramente determinista dominava, em São Paulo um liberalismo de fachada - cartáo de visitas para questóes de cunho oficial -, convivia com um discurso racial, prontamente acionado quando se tratava de defender hierarquias, explicar desigualdades sociais. A teoria racial, quando utilizada, cumpria o papel de deixar claro como para esses juristas falar em democracia não significava discorrer sobre a noçăo de cidadania. Assim, se em Recife o indivíduo foi sempre entendido como uma amostra de seu grupo; em São Paulo, com a adoçáo de um liberalismo de cunho conservador e cada vez mais antidemocrático, a questáo da cidadania como que desaparecia e com ela a vontade do indivíduo. Como dizia uma artigo publicado em 1914 na revista da escola paulista, " 0 individuo no Brasil sempre foi letra mortal... e afinal, quem se importa". 


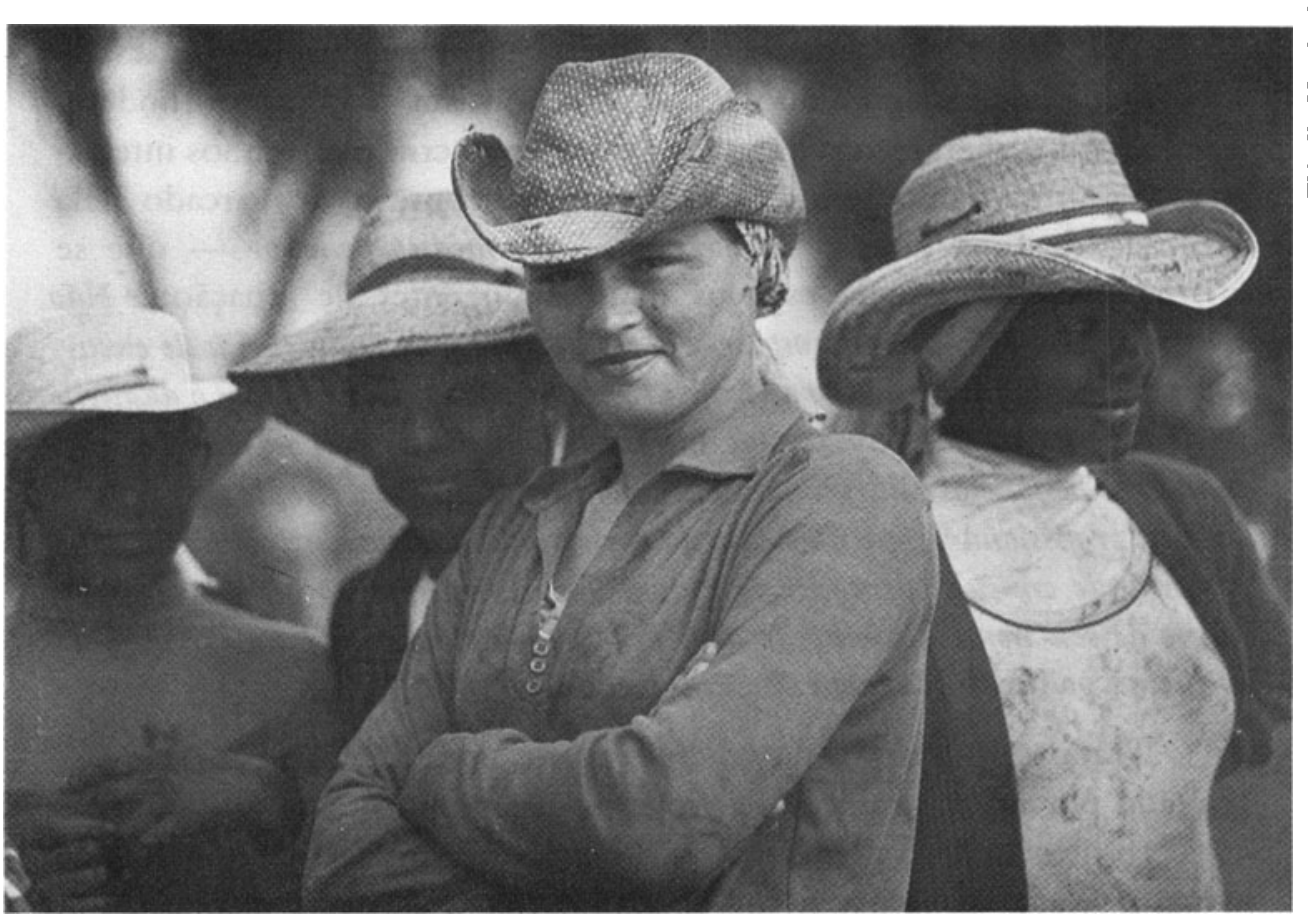

"Ao mesmo tempo que uma visáo determinista gerou o fortalecimento de uma interpretaçăo racial para a formagf̆o da nacăo, em contraposiça levou a um esvaziamento do debate sobre a cidadania e sobre a participafáo do individuo"

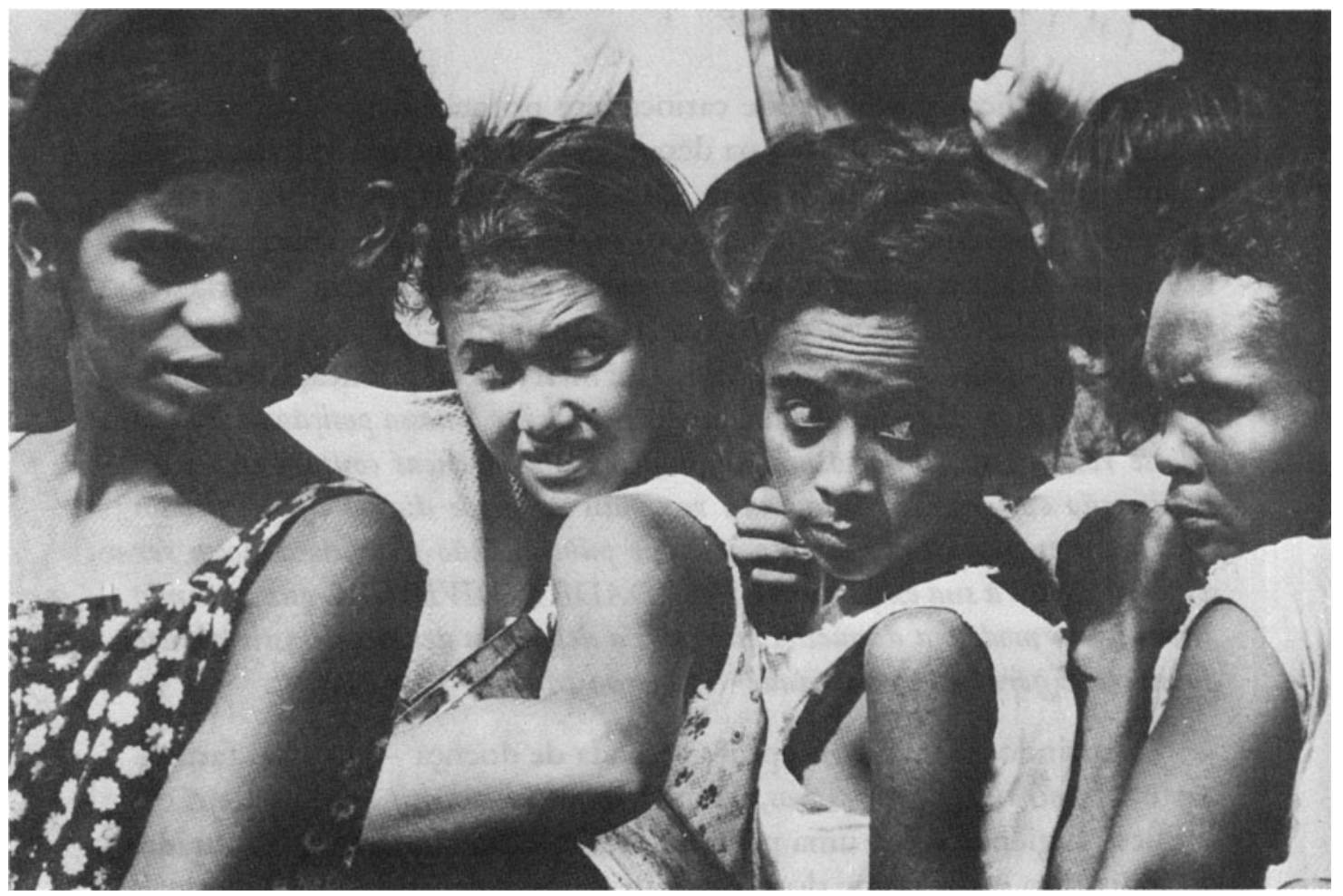


Por fim, restaria discorrer sobre o universo das faculdades de medicina, aonde a figura do médico e do cientista social se confundem, dando lugar à imagem do higienista e do perito criminal, ambos intelectuais de intervenção política e social. Esse contexto é marcado pela ascensáo de uma nova personagem - o "médico político" - que se afirma pela procura de espaços mais abrangentes de atuaçáo: "Não senhores! Se é bello de contemplar-se o espectaculo singelo da caridade encarnada no medico que allivia padecimentos individuaes, não é menos o daquelle que compenetrado do papel social da medicina politica entorna para todos os lados seus beneficios allargando incommensurapelmente o circulo de suas atividades profissionaes, que na escala da perfectibilidade dos sentimentos auxilia a sociedade em sua passagem do egoismo ao althruismo. $O$ medico moderno digno de seu nome e condicfäo deve practical-a plenamente no exercicio da medicina politica" (Gazeta Medica da Babia, 1896:398).

Trata-se, portanto, da emergência de um saber médico no país, pautado por novas ambiçōes e projetos, que fazem desses profissionais concorrentes a altura na disputa pela hegemonia intelectual no país. Os alvos, porém, sáo específicos: enquanto no interior da faculdade de medicina da Bahia percebe-se uma atenção especial aos temas da medicina criminal e toda uma batalha personificada por Nina Rodrigues nesse sentido; no Rio de Janeiro já será a pesquisa e atuaçăo na área da higiene pública e da epidemiologia que congregaráo o grosso dos esforços.

Os médicos da faculdade carioca, em primeiros lugar, buscavam sua originalidade e identidade na descoberta de doenças tropicais, como a febre amarela e o mal de Chagas, que deveriam ser prontamente sanadas pelos programas hygienicos, prova maior de avanço e contribuiçáo. Frente aos números alarmantes, que revelavam que no Brasil morria-se, acima de tudo, por causa de moléstias contagiosas (3), partiam esses profissionais para uma ampla política de intervençáo pública, tornandose cada vez mais abrangente sua atuaçáo. "Triste a nossa posifüo enquanto náo se resolver entre nós o magno problema das doenfas contagiosas, e da vaccinafáo obrigatoria. Esta cada vez mais se impóe diante dos progressos realizados entre nós em relafaio à sauide puiblica, náo podendo a nosso ver servir de escusa dे sua execuçao a LIBERDADE DNDTVDUAL que seguindo a tendencia moderna daquelles que mais a defendem deixa de existir diante do interesse geral da comunidade" (Boletion Médico, 1910:107).

Partindo de uma concepçáo alargada de doença - na qual fariam parte não só os doentes físicos, como mentais e morais - insistiam os médicos higienistas em uma primazia de sua atividade frente à vontade do indivíduo e em nome dos desígnios da coletividade. $O$ profissional 
médico separava-se, dessa maneira, da ingerência de outros políticos e especialistas, exigindo independência em sua atividade, e autonomia no seu diagnóstico. É esse o tom do discurso de Oswaldo Cruz quando em 1904, antes da famosa Revolta da Vacina, declarava ao Jornal do Comércio:" Preciso de recursos e da mais completa independéncia de ação. O governo me dará tudo que necessito, deixando-me lipre na escolba de meus auxiliares, sem nenhuma interferéncia política". A ditadura sanitária era a única resposta que esses médicos conheciam diante da realidade desse país, descrito por Miguel Pereira, "como um grande hospital".

Os médicos baianos, por sua vez, procuraráo pela mesma originalidade nacional, só que a encontrarão no cruzamento racial, que parecia representar, paradoxalmente, não só o nosso maior mal, como também a nossa suprema diferença. Com efeito, a referência ao tema da miscigenação, ou "do problema negro", como era normalmente caracterizado, era uma constante nesse local. Entendido como o grande fator que explicaria " nossa inferioridade como povo" (Gazeta Medica, 1933:7), ou "nossa fraqueza biologica", o cruzamento racial parecia significar uma questão fundamental.

É somente a partir desse contexto de debate que se pode entender a introduçáo da questáo da medicina legal nesses recintos. Na condiçáo de médicos peritos, especializados no estudo da mente do criminoso, defenderão a criação de uma prática diversa e especial. Afinal, estava em jogo a supremacia e autonomia no reconhecimento do crime e na qualificação do criminoso: "Para um povo de populafão beterogénea como o brazileiro, a identificafāo craniologica das rafas adquire em medicina legal uma importancia maxima", dizia o artigo de Nina Rodrigues, publicado em 1902 na Gazeta Medica da Babia.

Adotando os métodos da escola positiva italiana, cujo grande teórico era Cesare Lombroso, os médicos baianos estabeleciam correlaçóes rígidas entre aspectos exteriores e interiores do corpo humano, considerando a miscigenação, por princípio, um retrocesso, um grande fator de degeneração. Dessa maneira, os exemplos de embriaguez, alienação, epilepsia, violência ou amoralidade passavam a ser utilizados como provas da correçáo dos modelos darwinistas sociais em sua condenaçáo ao cruzamento, em seu alerta à imperfeição da hereditariedade mista. Sinistra originalidade encontrada pelos peritos baianos: o enfraquecimento da raça permitia não só a exaltação de uma especificidade da pesquisa nacional, como uma identidade do grupo profissional.

Mas se existem singularidades que distinguem essas duas faculdades de medicina é possível dizer que as relaçōes foram sobretudo mar- 
cadas pela camaradagem e por uma divisảo de áreas quase consensualmente aceita. A Bahia vinha com a antropologia criminal, o Rio de Janeiro com as pesquisas sobre medicina tropical. Enquanto para os médicos cariocas tratava-se de combater doenfas, para os profissionais baianos era o doente, a população, que estava em questão.

\section{Entre o veneno e o antídoto}

De fato, se existiu alguma disputa pela hegemonia intelectual, essa se evidenciou entre os profissionais de direito e os de medicina: ora o remédio, ora a lei; o veneno para uns, o antídoto na mão dos outros. Se para os bomens de direito a responsabilidade de conduzir a naçáo estava vinculada à elaboração de um código unificado, para os profissionais médicos somente de suas máos sairiam os diagnósticos e a cura dos grandes males que assolavam a naçáo. Enquanto os profissionais médicos pretendiam curar as doenças e nossas heterogeneidades, bacharéis acreditavam encontrar no direito uma prática acima das diferenças sociais e raciais observadas.

Pensado nesses termos, o argumento racial continuava oportuno, quando obliteradas as suas conclusóes mais radicais. Justificava teoricamente desde a construçáo de projetos políticos conservadores, até a existência de hierarquias rígidas, agora cientificamente explicadas. Dessa maneira, se ao adotar o jargáo evolucionista e racial essas elites letradas acabavam assumindo uma espécie de consciência do atraso, encontravam também respaldo para redimensionar uma discussáo sobre a igualdade entre os homens e, por conseguinte, sobre critérios de cidadania.

O mesmo contexto que encontra em um projeto liberal a solução para a nova configuração política, procura nas teorias deterministas subsídio para transformar diferenças sociais em barreiras biológicas fundamentais. Ante a liberdade prometida pela aboliçáo e a igualdade oferecida pela nova Constituição, parecia imperativo repensar a organizaçáo desse novo país. Como dizia o artigo de 21 de dezembro de 1920 do Correio Paulistano," os homens não nascem iguaes absolutamente, suppöe-se uma igualdade presumida pela lei sem o que não baveria lei...".

Transformada em utopia pelos cientistas nacionais, a igualdade conseguida mediante as conquista políticas era negada em nome da natureza e imediatamente transformada em uma ilusão (Corrêa, 1983). Era exatamente essa a tese de Nina Rodrigues quando em 1906 dessa maneira pronunciava-se na "Gazeta Médica": "Não pode ser admissível em absoluto a igualdade de direitos sem que haja ao mesmo tempo, pelo menos, igualdade na evolufäo... No bomem alguma cousa existe além do individuo... 
Fazer-se do individuo o principio e o fim da sociedade, como sendo o espirito da democracia, é um exagero da democracia, é um exagero da demagogia... As ideas da Revolufão Franceza até hoje não se puderam concilliar pois abherrant inter se...".

No entanto, mais interessante do que nomear a batalha existente entre direito e medicina, ou do que refletir sobre o impacto dessas idéias é pensar sobre a originalidade de sua utilização. Falar da adoçáo das teorias raciais no Brasil implica refletir sobre um modelo que incorporou o que serviu e esqueceu o que náo se ajustava. Ou melhor dizendo, procurou nessas teorias justificativas para expulsar a parte gangrenada da populaçáo, sem deixar de garantir que o futuro seria branco $e$ ocidental.

É o próprio modelo que se redefine em função da matriz que o origina, velhos nomes com novos significados, o que comprova como, no Brasil, raf̧a era um conceito original e negociado. Náo se trata dessa maneira de entender a adoção das teses raciais como mero reflexo, cópia desautorizada, mas antes indagar sobre seus novos significados contextuais. A idéia é nomear e resgatar o impacto dessas teorias, atentando para o contexto político em que elas se inserem, sem deixar de lado a dinâmica de reconstruçáo de conceitos e modelos.

\section{Quem fala em raça não prevê o cidadão}

Fazendo as vezes de uma ideologia da cultura nacional, as teorias raciais cumprirão no Brasil papéis distintos. Enquanto discurso leigo vão se contrapor à Igreja e à influência religiosa. Legitimarăo, ainda, as falas dos grupos urbanos ascendentes, responsáveis pelos novos projetos políticos e que viam nessas idéias sinais de modernidade, índices de progresso.

Mas, se a questáo racial foi operante na medida que apontava para determinadas compreensóes da sociedade, impediu ou relativizou a realização de outros debates. Ao mesmo tempo que uma visão determinista gerou o fortalecimento de uma interpretação racial para a formaçáo da nação, em contraposição levou a um esvaziamento do debate sobre a cidadania e sobre a participação do indivíduo. Entendendo o sujeito como o resultado de seu grupo racio-cultural, esse tipo de teoria tendeu negar a vontade individual frente a coerçáo racial e ao determinismo do grupo somático de origem (Arendt, 1973). Com efeito, tais doutrinas tinham como característica a oposiçáo năo apenas ao humanismo do século XVIII, como à filosofia do voluntarismo, desqualificando o princípio universal da igualdade, herdeiro da Revolução Francesa. Por outro 
lado, como sugere Louis Dumont (1966:320), esses dois modelos não estariam tão distantes: o racismo como fenômeno recente " responde sob uma forma moderna a uma funçáo antiga". Reintroduzido já em inícios do século XIX, na Europa, enquanto princípio de hierarquizaçáo em sociedades desigualitárias, o dogma racial pode ser de certa forma entendido como um estranho fruto, uma perversão do Iluminismo humanitarista, que buscava naturalizar a desigualdade em sociedades só formalmente igualitárias.

Quando se trata de pensar no caso brasileiro, o que se nota é a emergência de dois debates contemporâneos: de um lado, o enraizamento de um modelo liberal jurídico na concepção do Estado; de outro, o paralelo enfraquecimento de uma discussão sobre a cidadania em funçáo da retomada do debate sobre a questão da igualdade (tendo como base as conclusóes deterministas raciais). Teorias formalmente excludentes, racismo e liberalismo conviveram, em finais do século, merecendo locais distintos de atuaçáo.

É possível dizer que no Brasil desenvolveram-se formas de sociabilidade diversas, nas quais a afirmaçáo do igualitarismo das Luzes e dos Direitos dos Homens pode existir de maneira difusa por causa da ausência da noçáo de direitos dos cidadáos. Em uma sociedade na qual a falta do indivíduo, das instituiçōes e do formalismo do Estado - táo desfigurado em meio à dispersão dos poderes locais - era fato, as teorias raciais pareciam estar no lugar, à medida em que o problema da nacionalidade como que escapava do plano da cultura para se transformar em uma questão da natureza.

Fazendo uso dos instrumentos que possuíam, esses homens de sciencia encontrarão uma convivência extravagante entre discurso liberal e racial. Se o primeiro constará do texto da lei, das falas oficiais, o segundo surgirá nos romances naturalistas, nas teses científicas. De um lado os bomens de medicina, que viam na mistura das raças o nosso maior veneno e se responsabilizavam pelo antídoto; de outro, os homens da lei, que apenas teoricamente se afastavam desse debate, pois apesar da defesa formal de um Estado liberal, na prática, temerosos com os efeitos da Grande Guerra e da mestiçagem acelerada, ponderavam "...sobre a juste$z a$ de se agir sobre o perfil de nossa populafão, composta por raças tão desiguais, e talvez pouco preparadas para o exercicio da cidadania" (Revista da Faculdade de Direito de Recife, 1919).

Além disso, se nessas esferas institucionais é muitas vezes como um discurso culpado - e cientificamente legitimado - que o argumento racial de análise social aparece referido, o mesmo náo pode ser 
dito de outros meios, nos quais esse modelo científico determinista pode ser assumido sem qualquer receio. Nos discursos do dia-a-dia, na representação popular, nos jornais de circulação diária, é quase corriqueiro o argumento que traduz a ciência em termos populares e encara a raça como uma questão de importância fundamental nos destinos da nação. " Simplificando o que tão bem se diz nas teorias scientificas, é através da rafa que se determina os destinos de um povo, da najáo... ", dizia o jornal Correio Paulistano em 1901.

É mais uma vez essa confusa relaçáo entre esferas pública e privada - tema de reflexáo de vários ensaistas nacionais (4) - que pode ser recuperada. Sáo dois modelos que, nesse contexto, parecem cumprir um acordo tácito, uma divisão entre locais distintos de inserção: o universo oficial, o espaço familiar. Com efeito, se essa visão racial da naçáo partiu dos estabelecimentos científicos, esteve sobretudo presente no domínio das relaçóes pessoais, das vivências cotidianas, das experiências mais intimistas.

Dessa maneira, se vai longe o contexto intelectual de finais do século passado; se já não é mais cientificamente legítimo falar das diferenças raciais a partir dos modelos darwinistas sociais, raça permanece, porém, como tema central no pensamento social brasileiro.

Por vezes é a visão otimista freyriana que prevalece transformando o país numa grande imagem de convivência racial pacífica e idílica. É de novo a rafa que aparece em expressóes como esse é um sujeito de raf̧a, voce vale quanto vale a sua rafa, vai na raça, entre tantas outras que falam de uma certa identidade nacional ainda pautada por uma coloração singular. A raça continua, também, presente em sua asserção mais negativa, que busca vincular aspectos exteriores a certas deformaçóes morais. É esse o discurso policial, a fala que preconceitua no cotidiano da violência.

São muitas faces que repóem o mesmo tema e que revelam, em seu conjunto, de que maneira o argumento racial é ainda operante como representação nacional. "Da cor da raça, cheiro e sabor", dizia o samba enredo da Unidos de Salgueiro em 1992, como a comprovar que náo estamos tão distantes das representaçóes de finais do século passado. Afinal, nesse e em outros locais, o país é ainda desenhado, como dizia Nina Rodrigues, com uma certa cor interessante e nesse sentido muito particular.

\section{Referências bibliográficas}

AGASSIZ, Louis (1807-73). A journey in Brazil. Boston, s.e., 1868. 
AIMARD, Gustave. Le Brésil nouveau. Paris, E. Dentú (ed.), 1888.

ARENDT, Hannah. The origins of totalitarism. New York, Harvest, 1973.

BORELLI, Silvia Helena Simōes (org.). Indios do estado de São Paulo. São Paulo, Yankatu, 1984.

CANDIDO, Antonio. O discurso c a cidade. São Paulo, Duas Cidades, 1993.

CORREA, Mariza. As ilusóes da liberdade. A escola Nina Rodrigues e a antropologia no Brasil. Săo Paulo, 1983. Tese (Doutoramento), Universidade de Săo Paulo.

DA MATTA, Roberto. Você sabe com quem está falando? In: Carnavais, malandros c herbis, $3^{\mathrm{a}}$ ed. Rio de Janeiro, Zahar, 1981.

DUMONT, Louis. Homo bierarchicus. Essai sur le systeme de castes. Paris, Gallimard, 1966.

FREYRE, Gilberto. Casa-grande ér senzala. Rio de Janeiro, José Olympio, 1930.

GOBINEAU, Arthur. Essai sur $l$ inegalite des races humaines. Paris, Gallimard-Pleiade (1 ed. 1853), 1983.

HALL, Michael. Reformadores de classe média no Império brasileiro e a Sociedade Central de Imigraçăo. Revista de História, v.53, n.105, p.148-160, 1976.

HOBSBAWM, Eric. A invenf̧a das tradiçóes. São Paulo, Paz e Terra, 1987.

HOLANDA, Sergio Buarque de. Raizes do Brasil. Rio de Janeiro, José Olympio, (1ª ed. 1936), 1979.

LACERDA, João Batista. Sur le métis au Brtsil. Paris, Imprimerie Devougue, 1911.

LOMBROSO, Cesare. L inomo delinquente. Roma, s.e., 1876.

MICELI, Sergio (org.). Histrria das Ciéncias Sociais no Brasil. Săo Paulo, Vértice/IDESP, 1989.

MONTEIRO, John. Tupis, Tapuias e a história de São Paulo. Novos Estudos Celrap, 1992.

NOGUEIRA, Marco Aurélio. As desventuras do liberalismo. Joaquim Nabuco, a monarquia e a República. Rio de Janeiro, Paz e Terra, 1984.

QUEIROZ, Maria Isaura Pereira de. Identidade cultural, identidade nacional no Brasil. In: Tempo Social 1. Sáo Paulo, Edusp, 1989.

RAEDERS, Georges. O conde Gobineau no Brasil. 2ª ed. Rio de Janeiro, Paz e Terra, 1988.

RODRIGUES, Nina (1862-1906). Os mestiços brasileiros. In: Brazil Medico. Rio de Janeiro, s.e., 1890. 1933), 1959.

As rafas lmumanas e a responsabilidade penal no Brasil. Bahia, Progresso (1 ed. 
1899.

Metissage, dégénérescence et crime. In: Archives d anthropologie criminelle, Lion.

ROMERO, Silvio (1851-1906). O Brasil social. Rio de Janeiro. Typografia Jornal do Commercio, 1907. 1888), 1949.

História da literatura brasileira, $4^{a}$ ed. Rio de Janeiro, José Olympio. (1 $1^{\text {a }}$ ed.

SCHWARCZ, Lilia K. Moritz. Homem de sciencia e a rafa dos homens: cientistas, instituiföes e teorias raciais em finais do século XIX. São Paulo, 1993. Tese (Doutoramento), Universidade de São Paulo.

STOCKING JR., George W. Race, culture and evolution. Chicago, University of Chicago Press, 1968.

VENTURA, Roberto. Estilo tropical: bistória cultural e polêmicas literárias no Brasil. Săo Paulo, Companhia das Letras, 1991.

VIANNA, Oliveira. Populaf̧ốs meridionais do Brasil. Rio de Janeiro, José Olympio (1ª ed.: 1918). 1952.

\section{Notas}

1 A reflexāo e o material que compóem boa parte desse artigo fazem parte de um trabalho mais abrangente, apresentado originalmente como tese de doutorado, com o título Homens de sciencia e a rafa dos bomens: cientistas, instituiçóes e teorias raciais no Brasil de finais do século XIX. É preciso esclarecer, ainda, que foram adotados alguns critérios específicos para citação: os documentos e termos de época aparecem entre aspas e em itálico, enquanto os comentários de críticos contemporâneos constam apenas entre aspas.

2 As declarações de Von Ihering acabaram gerando inúmeras reaçóes, culminando na criação do SPILTN e de uma política mais direta de proteção. Sobre o tema vide também Borelli, 1984.

3 Em 1895, em um quadro de demografia sanitária publicado pela revista Brazil Medico (1896:62), a incidência de moléstias contagiosas era aterradora. Em primeiro lugar no índice de mortalidade constava a tuberculose a peste branca - , responsável por $15 \%$ das mortes no Rio de Janeiro. Seguiam-se em ordem de grandeza os casos de febre amarela, variola, malária, cólera, beribéri, febre tifóide, sarampo, coqueluche, peste, lepra, escarlatina, os quais todos juntos, representavam $42 \%$ do total das mortes registradas nessa cidade (1896:62).

4 A questão da delimitação ambígua existente no Brasil, entre domínio público c privado já foi tematizada, de formas diversas, por vários pensadores nacionais. Citamos aqui alguns: Holanda, 1979; Da Matta, 1981; Candido, 1993; Vianna, 1952. 


\title{
Resumo
}

Um grande laboratório racial: era essa a imagem do Brasil no final do séculı XIX. Construída pelos inúmeros viajantes que aqui estiveram, essa alusăo a um país de raças híbridas encontrava também acolhida entre os cientistas nacionais, que se congregavam nos diversos centros de ensino e pesquisa: os institutos históricos e geográficos, os museus etnográficos, as faculdades de direito e de medicina. Adotando modelos do determinismo racial coube a esses intelectuais, porém, o estranho papel de difundir um extremo pessimismo no que tange ao futuro dessa nação mestiça. $O$ desafio desse artigo, portanto, é compreender a originalidade do pensamento local, como também a convivência inesperada entre dois modelos supostamente antagônicos: liberalismo e racismo.

\begin{abstract}
In the late nineteenth century, Brazil was seen as a huge laboratory for racial experimentation. This view of a country of hybrid races, constructed by countless foreign visitors, was also accepted by the Brazilian scientists working in various teaching and research centers: historical and geographical institutes, museums of ethnography, law and medicine schools. Oddly enough, however, it was these intellectuals, believers in models of racial determinism, who popularized an extremely pessimistic view of the future of this nation made by miscegenation. The challenge faced by the present article is to apprehend the originality of local thinkers and the unlikely juxtaposition of two supposedly incompatible models: liberalism and racism.
\end{abstract}

Lilia Moritz Schwarcz é professora do Departamento de Antropologia da Faculdade de Filosofia, Letras e Ciências Humanas da USP. É autora, entre outros, do livro $O$ Espetáculo das rafas - Cientistas, instituifōos e questão racial no Brasil 1870-1930 (São Paulo, Companhia das Letras, 1993). 